\title{
No name, no game: Challenges to use of collaborative digital textbooks
}

\author{
Åke Grönlund $^{1}$ (D) Matilda Wiklund ${ }^{1} \cdot$ Rickard Böö $^{1}$
}

Received: 8 September 2017 / Accepted: 1 November 2017 / Published online: 20 November 2017

(C) The Author(s) 2017. This article is an open access publication

\begin{abstract}
Collaborative digital textbooks - comprehensive materials covering entire curriculums - are developing from being books in pdf format to becoming collaborative digital environments where teachers and students can communicate, engage in feedback and discussions, share and manipulate materials, test knowledge, and monitor results. This study investigates how these digital environments are used in school practice: How are the collaborative tools used to improve learning? Thirteen seventh- and eighth-grade classes, 370 students and 30 teachers in five Swedish secondary schools, were investigated over 1,5 years by means of questionnaires, classroom observations and interviews with teachers and students. Here, questionnaire results are presented, while observations and interviews serve to provide contextual insights. Collaborative tools were very little used; often teachers and students were not even aware of their existence. Most use was individual, students were left alone with the digital material. Students read or listened to the text and did not actively engage in learning by e.g. making notes or marking text. Most teachers did not use the material actively to help students understand and learn, most did not even check student results on automated tests. We conclude that the teachers have not incorporated the new, collaborative design of the digital textbook into their thinking regarding tools for teaching and learning and still regard it as a static book. This suggests that making full use of digital tools requires new ways of thinking of teaching, and that it takes more than providing digital tools to achieve this end.
\end{abstract}

Åke Grönlund

ake.gronlund@oru.se

Matilda Wiklund

matilda.wiklund@oru.se

Rickard Böö

rickard.boo@oru.se

1 Örebro University, Örebro, Sweden 
Keywords Cooperative/collaborative learning $\cdot$ Secondary education · Improving classroom teaching $\cdot$ Interactive learning environments $\cdot$ Pedagogical issues

\section{Introduction}

Collaborative digital textbooks (cDTB) are an emerging generation of teaching and learning materials transcending the prevalent e-book/pdf file format to become collaborative and dynamic digital work environments.

To date, DTB (without ' $C$ ') research has predominantly been concerned with the early versions, that is to say, traditional books in pdf format. These pdf books have been found to present benefits as well as challenges for teachers and students. DTB are reported to open up for teaching effectiveness and for student motivation (Embong et al. 2012) but teachers experience uncertainty in how to cope with them and still rely heavily on paper textbooks (Reints 2015) Students are reported to be reluctant to use digital textbooks (Daniel and Woody 2013; Woody et al. 2010).

Over the past few years, cDTB have developed from page fidelity, digital replicas of textbooks, 'book-in-box' (pdf files) to include a whole range of digital enhancements and study tools (McFadden 2012) covering entire curriculums. Beyond the intellectual content, cDTB contain tools for personal support to students, text manipulation, communication between students and teachers, and teacher support for planning, administration and monitoring. For this reason, we term them cDTB. The development has taken place as an effort to meet the perceived requirements of the digital world, including active involvement between learner and materials, among learners, and between teachers and learners. However, to make a difference to education, teachers' views of this new collaborative tool, and the ways in which they make use of it, are important. Therefore, this study investigates how the collaborative tools included in the CDTB are used by teachers and students to improve learning.

This was investigated in a multi-method study where 370 students and some 30 teachers in five secondary schools were followed over 1,5 years.

\section{Digital textbooks: DTB and cDTB}

\subsection{Definitions}

DTB are defined in many different ways throughout the research literature. Some definitions focus on their format as structured textual and visual content using a digital format (Knight 2015), others define them by means of device; as texts that include the familiar features of a textbook but in a digital form to be accessed with an app or via an Internet connection and to be read on an eBook reader, tablet, smartphone or computer (Dobler 2015; Yalman 2014). Further definitions add specific features, such as hyper-textual links, bookmarks, multimedia objects, interactive tools, possibilities for modifications, annotations and highlights, as well as search and cross-reference functions, illustrations and hotspots, and navigation mechanisms (Aharony 2015; Brueck and Lenhart 2015; RockinsonSzapkiw et al. 2012). Bozkurt and Bozkaya (2015) define interactive DTB as 
the improved extension of digital books in which users, the digital book, and the environment interact reciprocally.

Consequently, the terminology on digital textbooks and learning resources is not standardised, and often intention is confused with function and content with tools (Selander 2003:220). This poses a potential problem for both practitioners and scholars. In our study, DTB refers to coherent (digital) material covering entire curriculums, and, if collaborative tools are included, they become collaborative cDTB. cDTB contain a complete range of material, as required by the curriculum, can structure this material according to pedagogical ideas, and also offer tools to support students in their learning, such as exercises, tests, opportunities to have the text read, the chance to make notes and annotations, marking text, and communicating with teachers and other students. This comprehensiveness distinguishes them from digital learning resources, which cover only some aspects of the curriculum content, such as an app to practise multiplication or a video-recorded teacher presentation. It also distinguishes them from digital tools, which are general assistants that are usable for many tasks in many contexts but do not contain curriculum content. Examples include word processors, spreadsheets, and Google apps for education. Digital textbooks may contain any number of such learning resources and make use of a variety of tools in order to facilitate and support learning of the established curriculum content. This, for example, has been proposed in terms of digital enhancements of textbooks (McFadden 2012), augmentations (Brueck and Lenhart 2015) or learning scaffolds (Embong et al. 2012), albeit the insistence on its educational importance - a clear definition of this development of the textbook - is lacking,

\subsection{Collaborative digital textbooks}

Today's emerging generation of cDTB extend far beyond the book-in-box type that has been prevalent for years. In efforts to provide complete digital work environments, a number of tools serving various purposes have been included. Grönlund et al. (2017) investigated five contemporary products of this kind and found that the included tools fall into the following four categories: presentation aids, tools for working with texts, tools for communication, and teacher tools.

Presentation aids include tools for orientation and navigation in the textbook itself, for example, tables of content, search tools, bookmarks, and maps of the content. They also include multimodality, video and animations. Adaption to support students with various functional disabilities, such as dyslexia, is another important characteristic. This includes the option to change to "easy language", to have the text read (and select parts to read), adjust the speed of reading, and include visual cues in order to make it easier to follow the text as it is read, and to adjust the amount of information in view with the purpose of catering for different cognitive abilities. In addition, there are also options for visual adaption, including font size, background and text colour.

Learning support tools may include an integrated dictionary to explain technical terms. These can be both predefined and provide the option for students to make additions themselves.

Some cDTB also include integration with curriculum goals and requirements so that students can relate their work to the grading scheme. 
Tools for working with texts may include text marking, making notes in the text, creating personal word lists or notebooks, automated tests, and assignments. Documents can be shared for joint writing and formative feedback.

Teacher tools allow teachers to add material, share material, and receive online support. Some cDTB not only allow classroom teachers the opportunity to add material, but also to hide pre-produced material, which can be useful in order to avoid overloading students with reduced capability of some kind, e.g. dyslexics.

Tools for communication include various options for collaboration, including teacher and student messages, comments and responses in text, students sharing material with teachers (e.g. test results), and teachers sharing material with students, individually or collectively - for instance, by means of links - and students can share material with each other. Teachers can also share material with colleagues.

The perhaps most distinguishing aspect of collaborative digital textbooks in comparison with pdf ones is that they are based on a central database, not downloaded static copies. This means that content can be updated continuously, e.g. old videos can be replaced with newer ones. There are also tools for teachers and students to report errors and comments on the material and the tools to the cDTB providers.

The most interesting aspect of the list of tools mentioned above is the combination of them into a digital collaborative learning environment where many of the types of interaction that can be found in a physical classroom can take place in a coherent digital environment. This means that work with digital material does not have to be restricted to students working individually but can be extended to a blended classroom where tools are integrated.

In an earlier study (Grönlund et al. 2017) we surveyed five different cDTB products and, even though the sets of tools were fairly common across the board, we saw considerable variation in how the various tools were designed and arranged. Since learning is dependent on both the format of the text and the medium (RockinsonSzapkiw et al. 2012), tool design is obviously important; for tools to be used, both useful functionality and smooth operation/ease of use are required.

Beyond the design, one major problem with new tools is to fit them into users' ways of thinking. What is this new thing? Terminology is one issue - the kind of collaborative learning environments described here do not yet even have a name (as alluded to in the title of this paper). "Digital textbooks" makes people compare them to paper books. "Learning environment" is too unfocused to provide clear clues as to its uses. "Digital classroom" is a term used in so many contexts that it does not have a clear meaning, and it also gives a feeling of abandoning the physical classroom. Similarly, "digital learning resources" is too amorphous to provide a specific meaning. It could be almost anything.

The individual tools mentioned above are all available separately or in other, more well-known, packages. Text editing and commenting is available on virtually all word processors, messaging is available by e-mail, and communicating with students can be performed orally in the classroom. Moreover, there are numerous software packages that offer quizzes. However, using a large number of digital tools combined together in a package in a single uniform environment is very different from using them separately in multiple digital environments. A single environment means that both material and communication can be kept together, which both facilitates everyday work and provides a historical record. This means students can go back and review their work in 
preparation for exams, and teachers can monitor students' work. This can be virtually impossible, or at least create huge administrative overheads, when using different digital environments for different tasks, for example when comments are separated from the material on which they are commenting.

\subsection{Research on use of digital textbooks in schools}

Because cDTB are a very recent phenomenon, most existing research deals with DTB, the traditional static digital "book-in-box", typically pdf files replicating the paper book. The bulk of traditional research on educational uses of e-books (digital books in general) and DTB (digital textbooks produced for educative purposes but lacking in collaborative options) focuses on students' individual uses and perceived or measured outcomes in terms of, for example, grades, scores or reading speed (Daniel and Woody 2013; Sheppard et al. 2008; Woody et al. 2010; Yalman 2014;). This echoes the research literature on ICT in education in general - and even more so, the media debate - where digital tools are often seen as automatons replacing the teacher in guiding students through individual learning, rather than as tools in a learning process where the teacher is also present and active. Research on active teacher involvement in planning and working together digitally with students in learning activities using DTB or cDTB is less common.

While many digital learning resources are indeed self-instructing, cDTB are aimed at both teachers and students. They provide materials and tools which teachers can adjust to fit the situation. While automated tools may be very useful for many tasks, learning is not solely an individual practice that can be automated, but rather a social endeavour requiring social interaction. Not all knowledge is technical or universal; for example, the voting systems are very differently designed across democratic countries. These differences come from the social cultural contexts in which the different methods have been designed and through which they have evolved. Human teachers can explain such things, automatons cannot. From a technical and practical point of view, cDTB are conceived as focal points, platforms, facilitating teaching and learning by bringing comprehensive contents and tools together in an easy-to-use manner conducive to learning and supportive of teacher planning, monitoring and evaluation. This indicates a need to focus more on active teachers. Existing research indicates that the degree to which DTB are actively used by teachers and students in their courses differ dramatically between schools, classes and individual teachers. Knight (2015) outlines a four-level typology relating to the level of DTB use: integrated resource, core resource, related resource and peripheral resource.

Teachers and students experience both benefits and challenges with DTB. As noted by several studies, such benefits reported include flexibility, accessibility and attractiveness (Daniel and Woody 2013; Fletcher et al. 2012; Weisberg 2011). Findings from studies in higher education indicate that textbooks are generally considered to be reliable tools providing creditable information that supports and enhances students' understanding of critical concepts (Knight 2015). In studying early literacy training, Brueck and Lenhart (2015) present the benefits of the use of e-books; they offer an engaging medium for young readers, are easy to implement for classroom teachers, and offer opportunities for individual practice for all students. Some students are found to be more inclined to use reading resources when digital text is the medium (Wright et al. 
2013). E-books have also been shown to motivate children and students to become more active and investigative readers and to actively teach early literacy skills through narrations, animations, and interactivity features, including search capability, hyperlinks and multimodal enhancements. Aspects of interactivity and collaboration, in our study specific features in what we have termed cDTB, are presented as benefits by a range of studies (Knight 2015), but these are typically not included in the concept of DTB. The 2012 University Horizon Report notes that students expect new contentdelivery formats and accessibility options, making it possible to learn anytime, anywhere, access content on the Cloud and collaborate across time and physical space. They also want interactive, socially based, fully integrated, and inexpensive digital media (Johnson et al. 2012).

In contrast, challenges to DTB include a lack of student preference for e-books generally, which does not seem to be positively affected by greater familiarity (Sheppard et al. 2008; Woody et al. 2010; Yalman 2014). It is also reported that reading time increases significantly (Daniel and Woody 2013. A further challenge is that many teachers received their training before mobile technologies entered the educational arena, which may lead to insecurities about usage, instruction and incorporation and that some teachers are wary about adopting social media (Brueck and Lenhart 2015). To use DTB, or cDTB, teachers need to be familiar with them and their possibilities. Yalman (2014) studied teachers' and students' views, knowledge and experiences of ebooks, highlighting the importance of pre-service teachers learning about them in order to be able to use them in their professional lives. Teachers' understanding of the qualities of DTB and cDTB is another challenge. Reints (2015) is interested in how educational research can help teachers when developing, selecting and using quality textbooks. The author argues that the vital question is not 'what works', but rather why it works, and that a reliable theory of learning is consequently required to judge their quality. Generally, teachers' views of what can be achieved using digital tools do not appear to be so visionary. Both Tallvid (2016) and Holmberg (2016) found that technology uses that resembled traditional teaching were much more common than using collaborative tools and methods. Both papers find reasons that include traditional views of learning as an individual activity, school culture, and lack of knowledge of, and skills in using, information technology.

As shown above, cDTB set the scene for the entire learning environment; they guide didactics concerning both content and work methods. cDTB are much more flexible than paper books and allow the inclusion of materials and tools by the teacher: the fact that they provide both a comprehensive content and a learning environment equipped with many tools offers them a prominent role in the school, and indeed for the teacher who has chosen to use them.

Just as with traditional paper textbooks, both DTB and cDTB have the potential to make teaching more uniform across schools and teachers, in regard to both content and methods. cDTB are still an emerging technology, and, to date, they are not, to the best of our knowledge, compulsory anywhere, although they are strongly supported by some governments, e.g. in Denmark (Pålsson 2014). There is, however, an increasing demand as the alternative - to let teachers compile their own set of material for all courses - is both time consuming and risky, as it results in material with huge variations in coverage, methods, and quality. While there is a need for a coherent and quality controlled material and methods, it is important to understand the contents of DTB/ 
cDTB. They are not all the same, but contain different tools, different materials and support different teaching methods (Removed for review). Tools inform and form use to someone who has a hammer, everything looks like a nail (after Maslow 1966) - so it is important to understand what can be achieved with different tools, what cannot, and what negative implications different tools may bring.

Research on digital textbooks in schools, as we have seen, regard them as opportunities for learning connected to individual interactivity as well as communicative, cooperative and collaborative use, as providing tools with multimodal enhancements for teachers and students, and as offering flexibility, accessibility, attractiveness, engagement and motivation for teaching and learning. Nonetheless, despite the prominent role handled to the digital textbook and the educational importance of the features and tools added to the textbook by digitalisation, there is no comprehensive definition of these new features and tools agreed upon within the field of research.

\section{Method}

The study used several data collection methods, including questionnaires, classroom observational time studies and interviews with teachers, school leaders and students during the academic years 2015-16 and 2016-17. This mixed-methods approach was continued in the analysis phase, covering both quantitative and qualitative aspects.

Questionnaires directed to all teachers and students were conducted as online links in April 2016, asking general questions concerning perceived competence and use of the digital textbooks, tablets and interactive whiteboards (IWB). In addition, we listed the different functions of the digital textbooks and IWBs and asked about the degree to which these were known and used by the teachers.

Observations and interviews were conducted on three occasions, in November 2015 and April and November 2016. On each occasion we spent 2 days at each of the five schools, in total 6 days' visit per school. A total of 105 students and 63 teachers were interviewed. All school leaders (varying between schools from one to four) were also interviewed on each occasion. School leaders included the principal of each school and, in most cases, also other members of a management team, typically including assistant principals, project leaders or "IT pedagogues"; teachers assigned with the task of assisting the other teachers in IT matters.

All teachers were invited for interview and all who were present in school during the days of the interviews attended. Teacher interviews lasted 45-60 min. We also had individual discussions with teachers on different occasions, such as after class and in the coffee room.

Students from each class were invited. Selection was based on interest and teacher agreement (so as to avoid interference in school work). Typically, seven to ten students from each school took part on each occasion, in groups of two to four.

Both student and teacher interviews were semi-structured and covered not only the digital textbooks but also related issues such as hardware, networks and server systems, and teaching and learning practices. We asked about how they used the various technologies, what benefits and problems they saw, and what improvements they could think of, if any. 
The purpose of the interviews was to understand teachers' and students' views of technology use within the context of daily school work.

Interviews were audio recorded and transcribed. Interviews and observations from the two researchers were read by both plus a research assistant, and experiences from the different observations were compared. Both researchers are experienced in performing these types of interviews and observations, and also have several years' experience in teaching and school leadership in compulsory school.

We observed 82 lessons in total. The observational approach was overt, primarily non-participatory, and relatively systematic (Patton 2002). An observation protocol stating what we were looking for and how we should document this was used. We sat in the classroom (one researcher per lesson) taking notes and moving around if it was possible without disturbing the lesson. In some cases, we would pose questions to teachers and students while observing for clarification purposes or in order to understand what was taking place, and, in some cases, when possible, we conducted short follow-up interviews with teachers following the observed lessons. We observed lessons in mathematics, natural science, social science and languages. Observations primarily concerned teachers' and students' use of technology (What technology is used? Used how?), but also work patterns, for example, the proportion of teacher presentation, student individual work, and group work.

Both interviews and observations aimed at obtaining a deeper understanding of what is behind the numbers in the questionnaire. The questionnaire provided quantitative data regarding:

- Which tools and functions are known and used?

- For what and to what extent are they used?

- Which tools and functions are not known and/or not (frequently or at all) used?

The interviews and observations provided both internal (actor) and external (observer) views,

- What are the reasons for this use and non-use? Why did they use some tools and not others?

- What are the consequences for teaching and learning?

Data from the questionnaire form the primary material for the presentation in this article. Interviews and lesson observations add value by providing contextual insights concerning teachers' and students' views of importance for our analysis. Data from interviews and lesson observations are also referred to in the discussion.

\section{Case description}

The study involved five secondary schools in five cities across Sweden which were working together in a 3-year development project initiated and supported by three companies: Samsung Electronics, Atea Sweden, and Gleerups Education. While, over the past few years, there has been a strong focus in Sweden (and many other countries) on providing computers to schools in order to achieve a 
high computer density in school, "one computer per student", the thrust of this project was to provide a complete solution to what schools need in order to prepare them for the digital world, namely technology, learning material and change management capability. For this purpose, Samsung provided tablets to a total of 13 classes and interactive whiteboards to several classrooms in each school, Gleerups provided comprehensive collaborative digital textbooks (as per the cDTB definition above) covering all school subjects to all students and teachers, and Atea provided education in change management to principals and teachers assigned with supporting other teachers in the digitalisation process. Gleerups and Samsung also provided education to teachers regarding use of their products as well as support throughout the project.

Change and change management were the main focus of the project. Earlier experiences from school digitalisation had shown that the rapid increase in computers, tablets and networks in school had not resulted in any significant change (Skolverket 2013, 2016). There has also been a lack of teaching materials in school, not least because procuring tablets and laptops often consumes the entire school budget for teaching materials. This frequently left teachers having to search the Internet for free material which, on the one hand, consumes a large share of their time, and, on the other, results in material of varying quality being used. Providing cDTB and tablets together was seen as a way to ensure the availability of quality controlled teaching materials to all teachers.

In total, 380 students were involved. Moreover, some 70 teachers were involved, albeit to a varying degree, around half of whom formed the core team. Some of the schools were new to one-to-one computing but others had years of experience. The project started in the summer of 2015 and will continue until the summer of 2018 .

\section{Results}

This section reports the results of the questionnaire.

The students' questionnaire had a response rate of $79 \%$ (250 of 317 students) differing somewhat between the schools (lowest rate 52\% and highest rate $91 \%$ ).

In most cases, the failure to answer can be explained by individual students being sick or otherwise absent. At one school, problems with the e-mail addresses can explain non-response, but one school's low rate remains unclear. Based on teachers' responses to our inquiries, it appears that the inability of teachers to find and retrieve e-mails that were inadvertently directed to their and their students' junk e-mail boxes due to restrictive school spam filters was the primary reason. A total of 26 teachers responded, which represents $58 \%$ of the number of teachers suggested as potential project participants by the principals of the five schools involved in the project. Based on experiences from our visits to the schools, there is reason to believe that the principals' lists were exaggerated. The core team of teachers participating is rather half of the number on the principals' lists, and hence the real response rate is considerably higher.

To document the ways in which ways digital textbooks or environments are used in school practice to improve learning, the tables in this section draw on our survey data. A brief glance at reported cDTB use (Fig. 1) shows that the cDTB 


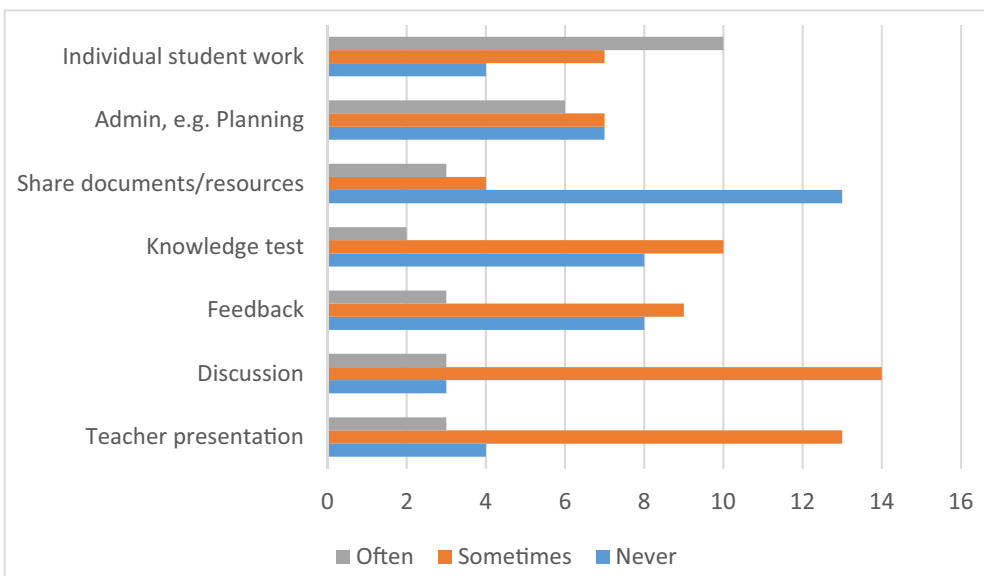

Fig. 1 Teachers' responses to the question, "How often do you use the cDTB for the following purposes?"

was generally most often used for individual student work $-60 \%$ of the teachers report such use as "frequent". The second most common use was for teacher planning (30\%), although high numbers of teachers nonetheless do not use it for this purpose. Sometimes it was used for communicational purposes, such as teacher presentation and discussion, but the sharing of documents and resources is essentially never performed (the sample size is small, thus $10 \%$ constitutes only three people).

The nature of the use is presented below, organised by the cDTB tools categories, including personal support to students, text manipulation, communication, and teacher support.

\subsection{Personal support}

As Table 1 shows, personal support functions are commonly used, at least by the students. Some two thirds of the students listen to the text at least some of the time. More than half of the students use the options for visual adjustment, and one quarter do this often. More than half of the students use the DTB on different technical platforms. Translation to other languages is also frequently used. Teachers' use of the personal support functions is not noticeably different from students', aside from the use of automated quizzes. These are used by almost all students and four fifths take them often. However, teachers do not generally monitor the results, only two teachers do so often, while $60 \%$ never do so.

The quiz function is there for three purposes. One is that students can conveniently check their understanding of the aspects of the material that lends itself to quiz-type questions. Another is that they can practise; they can perform the tests any number of times until they can get every question right. The third reason is that teachers can monitor student progress and take action when/if necessary. For example, if a student takes the same test ten times and never improves their score, the teacher might want to investigate the reasons behind this. Has the student not read the texts and done the exercises and is just guessing? Is the material beyond the capability of the student? 
Table 1 "How often do you use these functions?" (personal support functions: \%)

\begin{tabular}{|c|c|c|c|c|c|}
\hline & \multicolumn{4}{|l|}{ Students } & \multirow[t]{2}{*}{ Teachers } \\
\hline & $\begin{array}{l}\text { Never, don't } \\
\text { know of it }\end{array}$ & $\begin{array}{l}\text { Never, but } \\
\text { know it is there }\end{array}$ & Rarely & Often & \\
\hline Listen to the text & $1 \%$ & $32 \%$ & $42 \%$ & $25 \%$ & \\
\hline $\begin{array}{l}\text { Visual adjustment (back-ground } \\
\text { colour, font size) }\end{array}$ & $12 \%$ & $26 \%$ & $36 \%$ & $26 \%$ & $16 \%$ often, $36 \%$ sometimes \\
\hline Quizzes (automatically graded) & $3 \%$ & $3 \%$ & $15 \%$ & $79 \%$ & $\begin{array}{l}\text { Two teachers (out of 26) } \\
\text { often monitor students } \\
\text { results, another eight } \\
\text { sometimes, while } 60 \% \\
\text { never do it. }\end{array}$ \\
\hline $\begin{array}{l}\text { Use on different platforms } \\
\text { (computer, tablet, } \\
\text { smartphone) }\end{array}$ & $8 \%$ & $39 \%$ & $28 \%$ & $25 \%$ & $32 \%$ often $36 \%$ sometimes \\
\hline $\begin{array}{l}\text { Use the support button to } \\
\text { report errors or opinions }\end{array}$ & $34 \%$ & $44 \%$ & $14 \%$ & $8 \%$ & $4 \%$ often, $36 \%$ sometimes \\
\hline Translate to other languages & $35 \%$ & $31 \%$ & $25 \%$ & $9 \%$ & $4 \%$ sometimes \\
\hline
\end{tabular}

\subsection{Text manipulation}

Marking text, writing notes and adding bookmarks to particularly important pages are common ways of both remembering and focusing upon written material. Opportunities for this are available in digital books as well as paper ones, but cDTB offer some additional benefits such as more space for notes and the fact that the material cannot be damaged by repeated annotation.

Two thirds of the students did not mark text or make notes or bookmarks at all. Only some $10 \%$ did so often. Almost one third did not know the tools exist. The numbers were slightly higher for the teachers (Table 2).

\subsection{Communication}

Communication functions were very seldom used by, and were often not even known to, students and teachers. Seventy-eight percent of the students and approximately the same proportion of the teachers did not use the Comments function. Thirty-five percent

Table 2 "How often do you use these functions?"(text manipulation functions)

\begin{tabular}{llllll}
\hline & \multicolumn{2}{l}{ Students } & \multicolumn{2}{c}{ Teachers } & \\
\cline { 2 - 4 } & $\begin{array}{l}\text { Never, don't } \\
\text { know of it }\end{array}$ & $\begin{array}{l}\text { Never, but know } \\
\text { it is there }\end{array}$ & Rarely & Often & \\
\hline Notes & $21 \%$ & $47 \%$ & $22 \%$ & $10 \%$ & One teacher often, four sometimes \\
Bookmarks & $30 \%$ & $34 \%$ & $23 \%$ & $13 \%$ & Five teachers often, five sometimes \\
Mark text (colour) & $29 \%$ & $38 \%$ & $23 \%$ & $10 \%$ & Two teachers often, eight sometimes \\
\hline
\end{tabular}


of the students shared material with other students and $44 \%$ with teachers, but teachers did not share material with students in the same medium (Table 3). This is not to say they do not share at all, but rather in other media, most commonly their own webpage, where they list links to resources on the Internet and provide self-made material. They also frequently mention YouTube, Google apps for education, and various learning management systems.

\subsection{Teacher support}

The cDTB in this test allowed for teachers to add links in the text to other resources on the Internet or to self-produced material. As Table 4 shows, teachers generally do not use this option to share material with their students. This is despite the fact that a majority of the teachers say that the texts in the cDTB need to be complemented by other material to some extent $(65 \%)$ or often $(35 \%)$.

In addition, neither do teachers share materials with other teachers, with only one teacher reported doing so.

\subsection{Students' technical ability}

Regarding students' own views of their own digital capability, Table 5 shows that only $32 \%$ of the students always feel sufficiently skilled to use technology as required by schoolwork. Another $42 \%$ responded "almost always", and $26 \%$ that more often than occasionally they do not feel sufficiently skilled.

\section{Discussion}

Similar to the results reported by Embong et al. (2012) many teachers and students that we interviewed discussed their experiences of cDTB (although used more like DTB) in general as effective and motivating: "The students find it more fun to work with digital devices" (from interview, two teachers). Although some report that other digital tools are more motivating and the cDTB are sometimes considered uninspiring: "It does not work... too boring voice"; "It is not inspiring" (from interview, two teachers).

Table 3 "How often do you use these functions?" (communication functions)

\begin{tabular}{|c|c|c|c|c|c|}
\hline & \multicolumn{4}{|l|}{ Students } & \multirow[t]{2}{*}{ Teachers } \\
\hline & $\begin{array}{l}\text { Never, don't } \\
\text { know of it }\end{array}$ & $\begin{array}{l}\text { Never, but know } \\
\text { it is there }\end{array}$ & Rarely & Often & \\
\hline Comments (to teachers) & $21 \%$ & $57 \%$ & $19 \%$ & $3 \%$ & $\begin{array}{l}\text { One teacher often, } 5 \\
\text { sometimes, } \\
77 \% \text { never }\end{array}$ \\
\hline Share material with other students & $37 \%$ & $28 \%$ & $27 \%$ & $8 \%$ & \\
\hline Share material with teachers & $\begin{array}{l}32 \% \\
71\end{array}$ & $\begin{array}{l}24 \% \\
55\end{array}$ & $\begin{array}{l}16 \% \\
35\end{array}$ & $\begin{array}{l}28 \% \\
64\end{array}$ & One teacher often \\
\hline
\end{tabular}


Table 4 "How often do you use these functions?" (teacher support functions)

\begin{tabular}{llllll}
\hline & $\begin{array}{l}\text { Students } \\
\text { Never, don't } \\
\text { know of it }\end{array}$ & $\begin{array}{l}\text { Never, but know } \\
\text { it is there }\end{array}$ & Rarely & Often & Never, but know it is there \\
\hline Share materials with teacher & $32 \%$ & $24 \%$ & $16 \%$ & $28 \%$ & $\begin{array}{c}\text { One teacher often shares } \\
\text { with students } \\
\text { Three teachers often, } \\
3 \text { sometimes }\end{array}$ \\
\hline Add links to external materials & $44 \%$ & $31 \%$ & $21 \%$ & $4 \%$ & \begin{tabular}{c} 
Then \\
\hline
\end{tabular}
\end{tabular}

Similarly, in our classroom observations, we saw classrooms where the cDTB and other digital devices, such as the interactive whiteboards, appeared to function relatively well. Once the implementation phase was overcome, most students and teachers became confident users. The students repeatedly praised having all books and assignments on one device. They were pleased with not having to worry about forgetting textbooks anymore, or having loose papers crammed into their bags. Many teachers mentioned both the students and themselves as being motivated by the use of digital tools. Unlike the reports from Woody et al. (2010) and Daniel and Woody (2013), most students were thus positive about learning with DTB.

The teachers in our study, however, mentioned experiencing some uncertainty as to how to cope with the cDTB and our observations revealed that they did, in fact, generally use the $\mathrm{cDTB}$ in the same way they would use a paper textbook or a traditional DTB. This may be interpreted as indicating a reliance on the paper book tradition, in accordance with the results from Reints (2015). DTB appear to have developed in the described way - from 'book-in-box' (pdf files) to including many digital enhancements and study tools (McFadden 2012) to cover entire curriculums. In earlier studies, as well as in our study, it appears that teachers have not yet completely followed this development in their didactic choices of the resources available. We highlighted this issue in the background section, as we found research indicating that a major problem with new tools is to fit them in with users' ways of thinking. The results from the questionnaire reported in this paper confirm this, and in the interviews, teachers talked about the cDTB in terms of "the textbook" or "the digital textbook". Our observations also strengthened the impression that the digital textbooks were used in ways very similar to the uses of paper textbooks.

This paper set out to investigate how the emerging generation of collaborative digital textbooks - which has evolved from being books in pdf format to interactive and dynamic digital learning environments - is used in school practice. One important issue here is the possibilities for interactivity and collaboration made possible by these environments. Enhanced effectivity of collaboration is proposed

Table 5 Students' response to the question: "Do you feel you have sufficient technical skills to manage all school activities which involves technology use?"

\begin{tabular}{lllll}
\hline 1 (Never) & 2 & 3 & 4 & 5 (Always) \\
\hline $1 \%$ & $5 \%$ & $20 \%$ & $42 \%$ & $32 \%$ \\
\hline
\end{tabular}


by the possibilities to coordinate different tools for reading, co-writing, the sharing of documents, and communicating within the realms of the digital textbook. From this, our research question is derived: How are the collaborative tools used to make learning more effective?

The answer from this study is that they are only used very seldomly. The use we saw in the study - in the observations and interviews as well as in the questionnaire - still primarily resembles paper book reading, or reading a static pdf book. Students read books individually and answer questions on the text individually. They frequently use some tools which they feel facilitate reading, such as listening to the text, and some learning tools such as quizzes. Text manipulation tools, such as making notes and marking text, are very rarely used. Moreover, tools for communication between teachers and students and among students are not used at all.

Teachers do not use the digital textbooks to monitor student progress or results, for example, using the statistics on quizzes, but instead appear to see student textbook use as an individual activity. The use of some personal support functions, including speech synthesis and quizzes, is relatively high among students. The fact that teachers almost never follow up on student achievements on the quizzes suggests that teachers primarily view such quizzes as an individual student activity, not as a learning activity which they themselves should monitor or engage in for formative purposes.

The limited use of text manipulation tools means, as our observations and interviews confirmed, that when students go through the text again before a test it is in most cases as blank as it was when they initially accessed it. No traces of their earlier learning efforts are left. They cannot easily find the most important places, and they do not receive any help in remembering what they thought or discussed when they first read it or when the teacher presented something, as they did not take any notes. They can only rely on their memory. Not making notes or marking text also suggests a less active mode of reading.

These findings, in combination, may raise the concern that many students do not read texts in any depth. In interviews, teachers often complain that texts are too difficult for students. This would suggest a need for greater active reading, for example, marking and explaining unknown words but, in practice, it seems these are largely ignored. If students looked them up, they did not make a note of it, and, if they made a note, it was somewhere else, so when they re-read the text for a test they will need to search for the explanations once more, or, more likely, simply not bother as time then is short. Potentially, they just read or listened to the text while attempting to memorise it. Subsequently, they take the quizzes and hope that remembering those answers is sufficient for the final test.

Communication While sharing can be performed in many ways, one of the points of a flexible DTB is that the pre-provided material can be integrated with teacherprovided material. There is a definite benefit in having material in the same location, as students can easily find it when they read up for an exam, and the added material can be directly linked to the relevant parts in the pre-provided tests, which makes the linkage clearer to the students.

This diversity in locations to share material to some extent reflects established practices, and also the fact that many teachers do not know that sharing functions exist in cDTB. One effect is that this extra material is not readily available when students 
read up for a test, necessitating that they find it themselves once more. Even though it is typically known to them where the teacher shares (usually their own webpage), it adds an extra cognitive load to remember what extra material there is, where to find it, and how it relates to the textbook material. While the ability to organise material is one aspect of learning that everybody should incorporate, it adds to the cognitive load and thus requires some additional effort. At any given point in time, some students have more of this ability than others. At least some students will simply give up, as our observations and interviews have shown.

Students' technical ability One view often postulated is that young people generally are digital natives, implying that they know "everything" about the digital medium. This, however, should be examined more closely. We have seen above that many students do not know about many of the functions included in the DTB. Perhaps the teachers did not inform them in this regard (as they often did not know about the tools themselves) but, in any case, they did not find them despite the fact that that some tools such as colour-marking text and making notes and comments are available in almost any software.

\section{Conclusion}

This paper set out to investigate how the emerging generation of collaborative digital textbooks - which have evolved from being books in pdf format to dynamic and collaborative digital learning environments - are used in school practice. How are the collaborative tools used to make learning more effective?

We found that use principally resembles paper book reading, or reading a static pdf book. Students read alone and answer questions on the text individually. They frequently use some tools for facilitating reading, such as listening to the text, and some learning tools such as quizzes. Text manipulation tools, such as making notes and marking text, are seldom used. Tools for communication between teachers and students and among students are not used at all. Teachers do not monitor student progress or results, e.g. using the statistics on quizzes, but appear to see student textbook use as an individual activity. While this is a relatively small study, the fact that almost all research on DTB views them as electronic versions of paper books and test factors such as reading speed and text comprehension suggest that this kind of use is indeed typical.

This study followed the development over three semesters, 1,5 years, and did not see any change in this respect taking place over time. On the contrary, individual work was more common during the second year than during the first. It may be that change takes place slowly, that eventually the use of the interactive tools will increase. It may, in contrast, also be that it will not, that the view of DTB as just an electronic version of the paper book has become entrenched and there is a need for some external input or incentive - beyond what has already been done in terms of tutoring of the teachers - to change that view. Whether the interactive tools themselves are sufficiently useful or require redesign is impossible to say at this point, as teachers' lack of use is because, in general, they do not know about the tools (as confirmed in interviews).

What is clear from this study is that advanced tools require inspired teachers trying to achieve something new. Overall, pushing tools at teachers, as was seen in the schools 
studied here, is a method that may work to achieve basic level technology use but less so for advanced use, even though fairly ambitious training programmes in tool use and change leadership were included.

One aspect that we wish to highlight is that literature concerning cDTB, from the field of practice and research alike, has yet failed to propose a name (and a definition) for the new tool that properly does justice to the width and breadth of educational usages made possible by such collaborative digital environments. This lack is mirrored by our finding that teachers and students are predominantly using other, external, tools for practices for which cDTB do offer possibilities, i.e. until there is no proper name, there may not be a proper game. Teaching will stay with tradition rather than explore the new opportunities.

Open Access This article is distributed under the terms of the Creative Commons Attribution 4.0 International License (http://creativecommons.org/licenses/by/4.0/), which permits unrestricted use, distribution, and reproduction in any medium, provided you give appropriate credit to the original author(s) and the source, provide a link to the Creative Commons license, and indicate if changes were made.

\section{References}

Aharony, N. (2015). Factors affecting the adoption of e-books by information professionals. Journal of Librarianship and Information Science, 47(2), 131-144.

Bozkurt, A., \& Bozkaya, M. (2015). Evaluation criteria for interactive E-books for open and distance learning. International Review of Research in Open and Distributed Learning, 16(5), 58-82.

Brueck, J. S., \& Lenhart, L. A. (2015). E- books and tpack what teachers need to know. The Reading Teacher, $68(5), 373-376$.

Daniel, D. B., \& Woody, W., D. (2013). E-textbooks at what cost? Performance and use of electronic v. Print texts. Computers \& Education 62, 18-23.

Dobler, E. (2015). E- textbooks a personalized learning experience or a digital distraction? Journal of Adolescent \& Adult Literacy, 58(6), 482-491.

Embong, A. M., Noor, A. M., Hashim, H. M., Mahari Ali, R., \& Shaari, Z. H. (2012). E-books as textbooks in the classroom. Procedia - Social and Behavioral Sciences, 47, 1802-1809.

Fletcher, G., Schaffhauser, D., \& Levin, D. (2012). Out of Print: Reimagining the K-12 Textbook in a Digital Age. Washington, DC: State Educational Technology Directors Association (SETDA).

Grönlund, Å., Kempe, A-L, Böö, R. (2017). Collaborative Digital Textbooks - changing the game for students and teachers. Computers \& Education, in press.

Holmberg, J. (2016). Applying a conceptual design framework to study teachers' use of educational technology. Education and Information Technologies (2017), 22, 2333-2349. https://doi.org/10.1007 /s10639-016-9536-3.

Johnson, L., Adams, S., \& Cummins, A. (2012). The NMC horizon report: 2012 higher (education ed.). Austin, Texas: The new Media Consortium.

Knight, B. A. (2015). Teachers' use of textbooks in the digital age. Cogent Education, 2(1), 1015812. https://doi.org/10.1080/2331186X.2015.1015812

Maslow, A. H. (1966). The Psychology of Science. New York: Harper \& Row.

McFadden, C. (2012). Are textbooks dead? Making sense of the digital transition. Publishing Research Quarterly, 28, 93-99.

Pålsson, S. (2014) Digitaliseringen av skolan i Danmark [Digitalization of schools in Denmark] http://omvarld.blogg.skolverket.se/2014/03/12/digitaliseringen-av-skolan-i-danmark/

Patton, M. Q. (2002). Qualitative research \& evaluation methods (3rd ed.). Thousand Oaks, London, New Delhi: Sage Publications.

Reints, A. (2015) Keynote presentation: What works and why? Educational publishing between market and educational science. In Z. Sikorova, M. Horsley, T. Braga Garcia \& J. Rodríguez (eds 2013) The Thirteenth International Conference on Research on Textbooks and Educational Media. Ostrava: International Association for Research on textbooks and educational media (IARTEM), 15-34. 
Rockinson-Szapkiw, A. J., Courduff, J., Carter, K., \& Bennett, D. (2012). Electronic versus traditional print textbooks: A comparison study on the influence of university students' learning. Computers \& Education, 63, 259-266.

Selander, S. (2003). Pedagogiska texter och andra artefakter för kunskap och kommunikation. En översikt över läromedel - perspektiv och forskning. [Pedagogical texts and other artefacts for knowledge and communication. An overview of textbooks - perspectives and research]. In: Läromedel - specifikt -. [Textbooks - specifically]. SOU 2003:15.

Sheppard, J. A., Grace, J. L., \& Koch, E. J. (2008). Evaluating the electronic textbook: Is it time to dispense with the paper text? Teaching of Psychology, 35, 2-8.

Skolverket (2013) (The Swedish National Agency for Education) It-användning och it-kompetens i skolan [IT use and IT competence in school] Rapport 386. Retrieved from: https://www.skolverket.se/omskolverket/publikationer/visa-enskildpublikation?_xurl_=http $\% 3 \mathrm{~A} \% 2 \mathrm{~F} \% 2 \mathrm{Fwww5}$. skolverket.se $\% 2$ Fwtpub\%2Fws\%2Fskolbok\%2Fwpubext\%2Ftrycksak\%2-FBlob\%2Fpdf3005.pdf\%3Fk\%3D3005

Skolverket (2016) (The Swedish National Agency for education) IT-användning och IT-kompetens $i$ skolan (IT use and IT competence in school). Skolverket. Retrieved from: https://www.skolverket.se/omskolverket/publikationer/visa-enskild-publikation?_xurl_http\%3A\%2F\%2Fwww5.skolverket.se $\% 2$ Fwtpub\%2Fws\%2Fskolbok\%2Fwpubext\%2Ftrycksak\%2FBlob\%2Fpdf3667.pdf\%3Fk\%3D3667

Tallvid, M. (2016). Understanding teachers' reluctance to the pedagogical use of ICT in the 1:1 classroom. Education and Information Technologies, 21(3), 503-519.

Weisberg, M. (2011). Student attitudes and behaviors towards digital textbooks. Publishing Research Quarterly, 27(2), 188-196.

Woody, W. D., Daniel, D. B., \& Baker, C. A. (2010). E-books or textbooks: Students prefer textbooks. Computers \& Education, 55, 945-948.

Wright, S., Fugett, A., \& Caputa, F. (2013). Using e- readers and internet resources to support comprehension. Educational Technology \& Society, 16(1), 367-379.

Yalman, L. M. (2014). Preservice teachers' views about e-book and their levels of use of e-books. The Turkish Online Journal of Educational Technology, 13(2), 138-147. 